\title{
Effect of heat treatments on the hydrogen embrittlement susceptibility of API X-65 grade line-pipe steel
}

\author{
G ANANTA NAGU, AMARNATH ${ }^{\dagger}$ and T K G NAMBOODHIRI* \\ Department of Metallurgical Engineering, Banaras Hindu University, Varanasi 221 005, India \\ ${ }^{\dagger}$ Small Industries Service Institute, Industrial Estate, Varanasi 221 006, India
}

MS received 11 October 2002

\begin{abstract}
Delayed failure tests were carried out on hydrogen charged API X-65 grade line-pipe steel in as received (controlled rolled), normalized, and quenched and tempered conditions. The resistance to hydrogen embrittlement was found in the order of controlled rolled $>$ quenched and tempered $>$ normalized. The fracture mode in the hydrogen embrittled steel was ductile.
\end{abstract}

Keywords. Hydrogen embrittlement; delayed failure; HSLA steel; controlled rolling.

\section{Introduction}

High strength low alloy (HSLA) steels comprise a specific group of steels specially developed to impart higher mechanical properties than is obtainable from conventional carbon steels. HSLA steels are produced in the hot rolled condition and a few grades are produced as cold rolled sheet, with greater strength. Controlled rolling is generally adopted to obtain a fine-grain microstructure with a combination of high strength and toughness. American Petroleum Institute (API) grade steels fall into the category of HSLA steels. These steels are widely used as pipelines for carrying natural gas and petroleum products which often contain large proportions of $\mathrm{H}_{2} \mathrm{~S}$, a promoter of hydrogen entry into steel. Hence considerable effort has been directed to study the hydrogen embrittlement of line-pipe steels (Beevers et al 1988; Lopez et al 1996).

Hydrogen in small quantities can seriously damage the mechanical stability of many structural materials (Namboodhiri 1984). Hydrogen induced blistering and hydrogen embrittlement are the two damaging phenomena observed in line-pipe steels (Moore and Warga 1976). Considerable alloy development work has been carried out to make these steels more resistant to hydrogen (Ravi et al 1990).

The role of microstructure on the hydrogen embrittlement susceptibility of steels has been investigated extensively. In low carbon HSLA steels the most refined structure, obtained by direct quenching and tempering, has the greatest resistance to hydrogen embrittlement (Pussegoda and Tyson 1981). It has been reported (Vasudevan et al 1981) that twinned martensite exhibits greater susceptibility to hydrogen embrittlement than slipped martensite and bainite has an intermediate susceptibility. The

\footnotetext{
*Author for correspondence
}

morphology and nature of hydrogen trapping sites alter the hydrogen embrittlement susceptibility of HSLA steels (Pressouyre 1982). In a Ti bearing HSLA steel a fine distribution of semi killed TiC particles obtained by peak aging at $600^{\circ} \mathrm{C}$ yielded the greatest reduction in hydrogen embrittlement susceptibility (Lopez et al 1996). Grain boundaries, precipitates and dislocations act as hydrogen traps and could affect the hydrogen embrittlement susceptibility of materials. Decreasing the grain size increases the density of hydrogen traps and reduces harmful impurity segregation and improves the materials performance in the presence of hydrogen (Rath and Bernstein 1971).

Delayed failure is a characteristic feature of hydrogen embrittlement of steels (Troiano 1960). Hydrogen charged materials under static loading fail after a lapse of time. Generally there is an incubation period for crack initiation, a period of discontinuous crack propagation and final fracture. An upper critical stress above which failure is instantaneous, and a lower critical stress or static fatigue limit below which hydrogen induced failure does not occur, exist. While the incubation time is insensitive to the applied stress, the time to failure increases with decrease in stress.

In the present study the effects of normalizing as well as quenching and tempering on the hydrogen embrittlement resistance of controlled-rolled API X-65 steel were evaluated. Delayed failure tests and transmission as well as scanning electron microscopy were used.

\section{Experimental}

\subsection{Materials}

API X-65 grade line-pipe steel was supplied by the Rourkela Steel Plant of the Steel Authority of India, in the 
form of a spirally welded pipe with a wall thickness of $10 \mathrm{~mm}$. The chemical composition of the steel was analysed using a Polyvac 2000 emission spectrometer and is given in table 1 . Hydrogen charging of the specimens was done in a $0 \cdot 1 \mathrm{~N} \mathrm{H}_{2} \mathrm{SO}_{4}$ solution prepared from analar grade acid and triple distilled water.

\subsection{Heat treatments}

Samples were cut from the pipe and heat treated at $880^{\circ} \mathrm{C}$ for $30 \mathrm{~min}$ followed by either air-cooling (for normalizing) or water quenching. The quenched samples were immediately tempered at $600^{\circ} \mathrm{C}$ for $1 \mathrm{~h}(\mathrm{Q} \& \mathrm{~T})$.

\subsection{Metallography}

Transmission electron microscopy was done using a JEOL JEM 2000 CX microscope. Thin foils were prepared by mechanical polishing followed by electro-jet polishing in a solution of $10 \%$ perchloric acid $+90 \%$ acetic acid kept at $10^{\circ} \mathrm{C}$.

\subsection{Mechanical testing}

A Vickers hardness testing machine was used to measure the hardness of the steel. Tensile tests were done on smooth as well as centre-notched round tensile specimens of $4.5 \mathrm{~mm}$ gauge diameter and $18 \mathrm{~mm}$ gauge length using an Instron Universal testing machine. The notched specimens had a $60^{\circ} \mathrm{V}$ notch of $0.75 \mathrm{~mm}$ depth at the centre of the gauge length.

\subsection{Delayed failure tests}

A Mayes Unisteel stress corrosion testing machine was used to dead-load notched tensile specimens. These specimens were cathodically charged with hydrogen in an electrolyte of $0.1 \mathrm{~N} \mathrm{H}_{2} \mathrm{SO}_{4}$ using a galvanostatic circuit for $4 \mathrm{~h}$ at a current density of $10 \mathrm{~mA} \cdot \mathrm{cm}^{-2}$. Immediately after charging, the specimens were cleaned and electroplated with a thin layer of nickel to minimize hydrogen degassing. The charged specimens were dead loaded at various stress levels and the times to failure were noted. The stress at which the specimen did not fail for more than 7200 min was taken as the static fatigue limit.

\subsection{Scanning electron fractography}

The fracture surfaces of delayed failure samples were observed in a JEOL JSM 840 scanning electron microscope.

\section{Results}

\subsection{Material characterization}

Microstructure of the controlled rolled API X-65 steel is given in figure 1 , which shows acicular ferrite with little pearlite. As seen from figure 1a, the acicular ferrite has a grain size of $3-5 \mu \mathrm{m}$ with a high dislocation density. The interlamellar spacing of the pearlite in the controlled rolled steel was of the order of 0.2 to $0 \cdot 3 \mu \mathrm{m}$ (figure $1 \mathrm{~b}$ ). Figure 2 shows that the normalized steel had a coarser ferrite + pearlite structure. The 5 to $10 \mu \mathrm{m}$ size ferrite grains had fine precipitates and some dislocations. The fine grain size obtained by controlled rolling is lost by
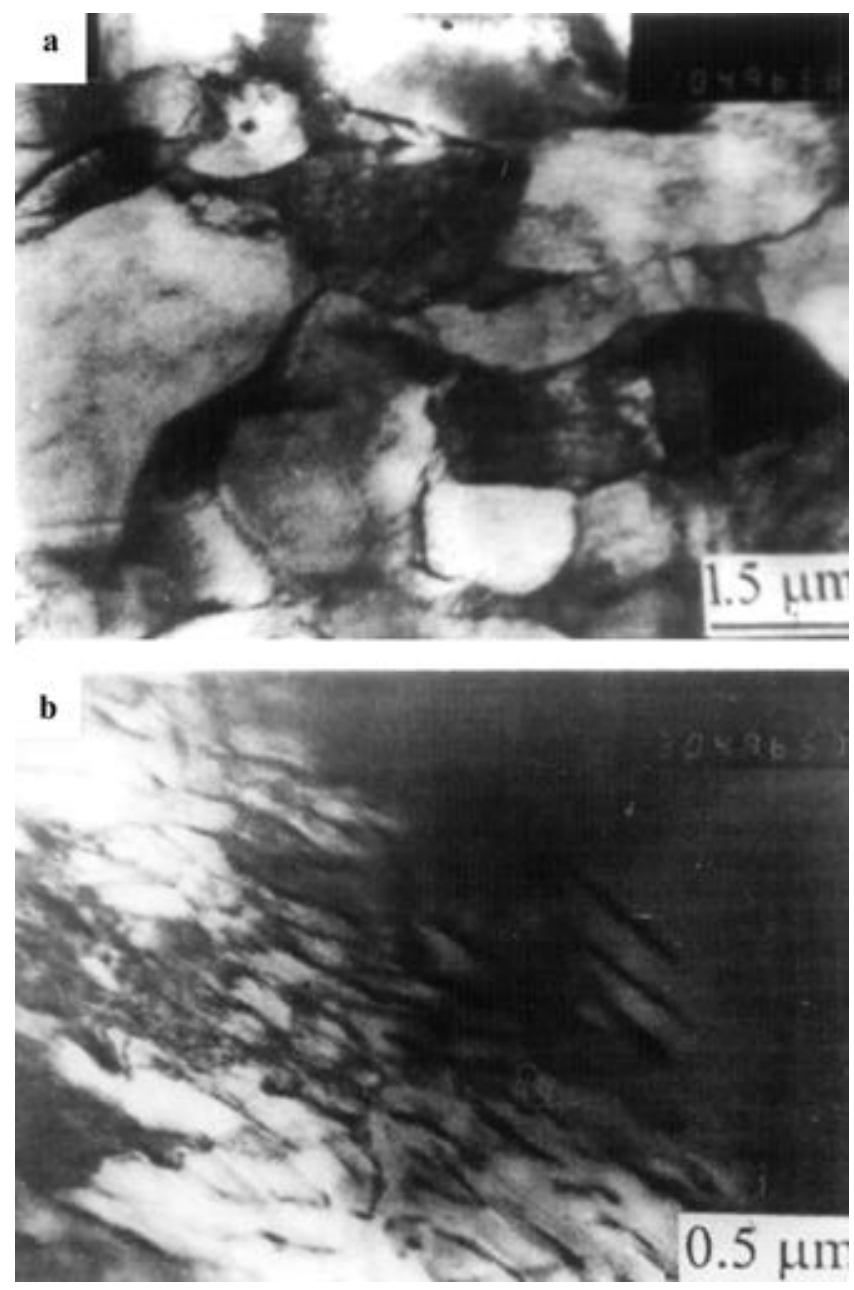

Figure 1. Microstructure of the controlled rolled API X-65 steel. a. Acicular ferrite and pearlite and $\mathrm{b}$. fine structure of pearlite.

Table 1. Chemical composition of API X-65 steel (wt.\%).

\begin{tabular}{cccccccc}
\hline $\mathrm{C}$ & $\mathrm{Si}$ & $\mathrm{S}$ & $\mathrm{P}$ & $\mathrm{Nb}$ & $\mathrm{Ti}$ & $\mathrm{V}$ & $\mathrm{Fe}$ \\
\hline 0.093 & 0.365 & 0.006 & 0.017 & 0.053 & 0.017 & 0.039 & Balance \\
\hline
\end{tabular}


normalizing. Figure 3 for the quenched and tempered steel shows low carbon lath martensite with a high dislocation density and spheroidized cementite particles.

The mechanical properties of API X-65 steel in various conditions are given in table 2. As expected, hardness, yield strength and ultimate tensile strength (UTS) are lowest in the normalized condition. The controlled rolled and quenched and tempered steels had comparable yield strengths, but the former had higher UTS and notch tensile strength and lower ductility than the latter. Notch

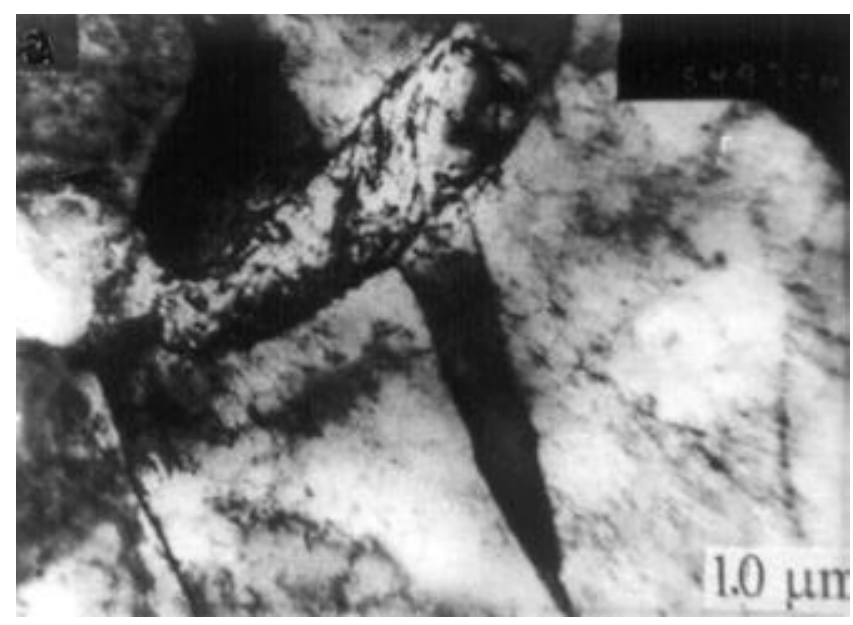

Figure 2. Microstructure of normalized API X-65 steel showing coarse ferrite and pearlite.

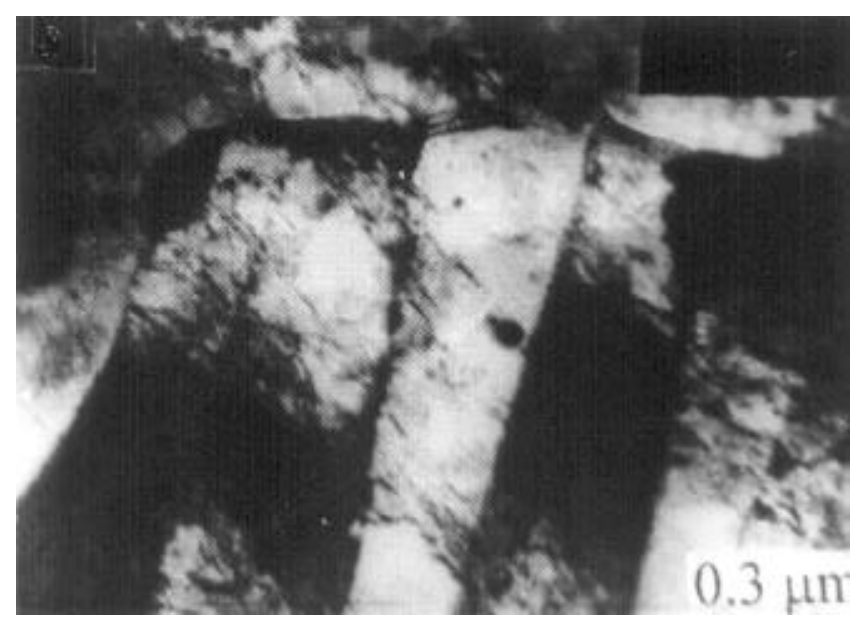

Figure 3. Microstructure of Q\&T API X-65 steel showing dislocated lath martensite and carbides. tensile strength of the steel in all the three conditions are about two to three times greater than their respective yield strength.

\subsection{Delayed failure behaviour}

The delayed failure curves of the steel in controlled rolled, Q \& T, and normalized conditions are shown in figure 4 . The steel in the controlled rolled condition showed the highest upper critical stress and static fatigue limit and the longest incubation period, about $1000 \mathrm{~min}$. These quantities were the lowest in the normalized condition while the $\mathrm{Q} \& \mathrm{~T}$ steel showed intermediate values. Figure 5 shows the delayed failure curves where the applied stress is plotted as a fraction of the notch tensile strength. Table 3 gives the delayed failure parameters of the steel estimated from figures 4 and 5. It is seen that the lower critical stress or static fatigue limit, the stress below which no hydrogen embrittlement failure occurs, for each condition, is well above the yield strength of the material.

\subsection{Fractography}

Figure 6 shows SEM fractographs obtained from steel in various heat treatment conditions. The mode of hydrogen induced failure in this steel is seen to be ductile. The fracture surfaces of steel show a duplex dimpled structure. The fracture surface is made up of a nearly uniform

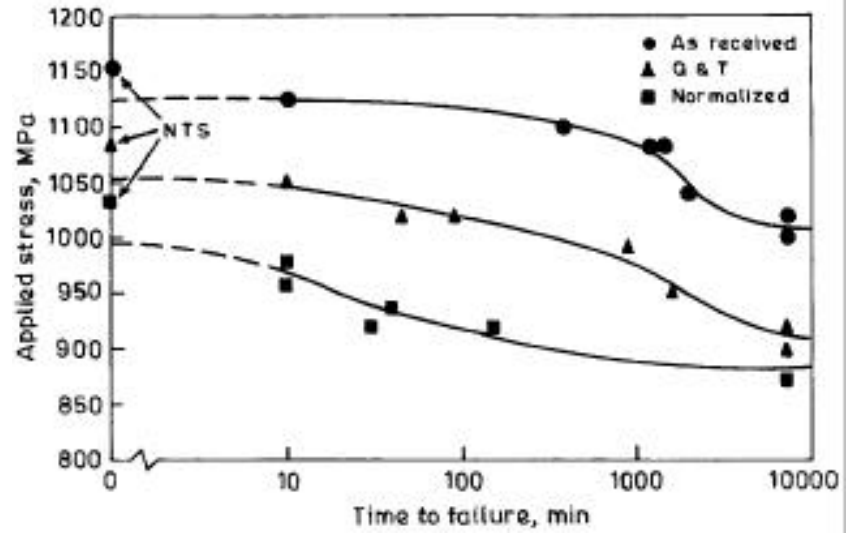

Figure 4. Delayed failure behaviour of API X-65 steel. All specimens hydrogen charged from $0 \cdot 1 \mathrm{~N} \mathrm{H}_{2} \mathrm{SO}_{4}$ for $4 \mathrm{~h}$ at a current density of $10 \mathrm{~mA} \cdot \mathrm{cm}^{-2}$.

Table 2. Tensile properties of API X-65 steel.

\begin{tabular}{|c|c|c|c|c|c|c|}
\hline Treatment & $\begin{array}{c}\mathrm{YS} \\
(\mathrm{MPa})\end{array}$ & $\begin{array}{l}\text { UTS } \\
(\mathrm{MPa})\end{array}$ & $\begin{array}{c}\% \\
\text { Elongation }\end{array}$ & $\begin{array}{c}\% \\
\mathrm{RA}\end{array}$ & VPN & $\begin{array}{c}\text { Notch tensile strength } \\
(\mathrm{MPa})\end{array}$ \\
\hline Controlled rolled & 490 & 605 & 28 & 74 & 194 & 1152 \\
\hline Normalized & 302 & 513 & 33 & 70 & 146 & 1034 \\
\hline QT & 485 & 564 & 30 & 79 & 203 & 1085 \\
\hline
\end{tabular}


distribution of large dimples in the normalized condition. In the other two cases, a relatively lower proportion of well-delineated large dimples was found in a matrix of finer dimples. The duplex distribution of dimples indicates that few dimples were initiated early in the fracture process, grew under the influence of hydrogen and the final fracture was preceded by the nucleation and growth of the fine dimples. Hydrogen influences the ductile fracture by altering any one or all of the initiation, growth and link-up of voids.

\section{Discussion}

During delayed failure tests, the incubation time is the time required for accumulation of hydrogen to a minimum critical concentration at regions of stress concentration where a crack is nucleated. This crack will propagate through the region where the accumulated critical concentration of hydrogen has reduced the cohesive strength of steel. The crack will stop beyond this region and it has to wait till a critical hydrogen concentration accumulates at its tip. Hence the crack propagation is discontinuous (Troiano 1960).

Hydrogen accumulates at regions of stress concentration by stress-assisted up-hill diffusion ( $\mathrm{Li}$ et al 1966). Presence of traps such as grain boundaries, interfaces, dislocations and precipitates strongly affect the kinetics of hydrogen transportation (Pressouyre 1982). The nature and morphology of these traps are also of great importance in the hydrogen susceptibility of materials (Bernstein et al 1982).

In the present steel, controlled rolling (as received), quenching and tempering (QT) and normalizing were chosen to attain variations in the characteristics of hydrogen traps. In the as-received, controlled rolled condition, the steel had very fine grains of acicular ferrite with a high dislocation density and a small proportion of fine pearlite. The grain boundaries, the dislocations and the ferrite-carbide interfaces act as hydrogen traps and delay

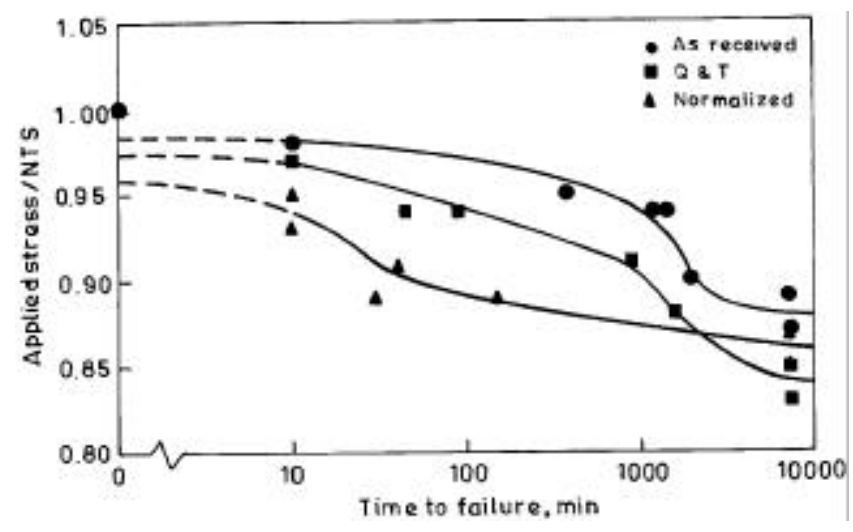

Figure 5. Delayed failure curves plotted between applied stress/ NTS and time to failure. the transport and accumulation of hydrogen at possible crack sites. This results in the long incubation period and failure times seen in figure 4 for the controlled rolled steel. The uniform distribution of hydrogen at the traps necessitates a high applied stress to cause the uphill dif-
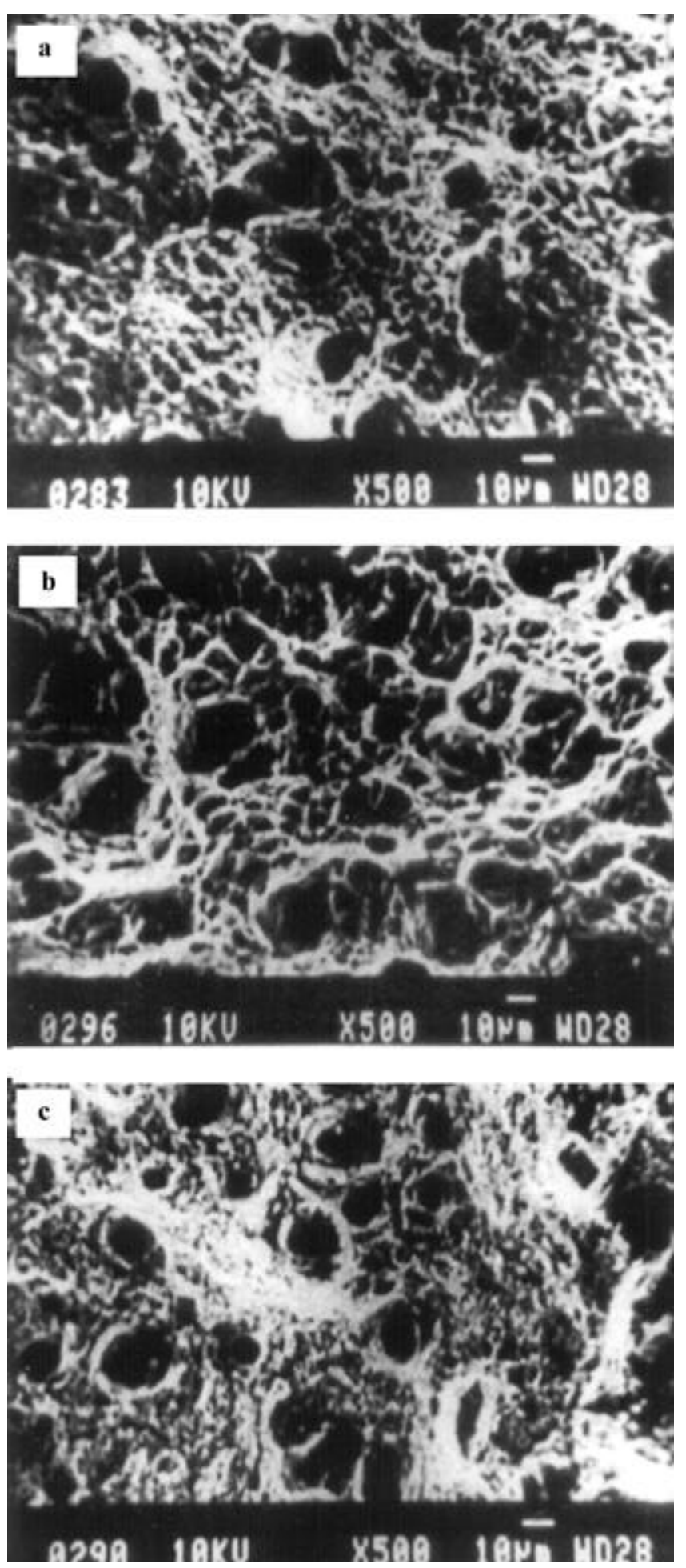

Figure 6. SEM fractographs from delayed failure tested API X-65 steel. a. As-received steel, b. normalized and c. Q \& T. 
Table 3. Delayed failure parameters of API X-65 steel.

\begin{tabular}{|c|c|c|c|c|c|c|}
\hline \multirow[b]{2}{*}{ Treatment } & \multicolumn{3}{|c|}{ Upper critical stress } & \multicolumn{3}{|c|}{ Lower critical stress } \\
\hline & $\begin{array}{l}\text { Stress } \\
(\mathrm{MPa})\end{array}$ & $\begin{array}{c}\text { Stress/ } \\
\text { NTS }\end{array}$ & $\begin{array}{c}\text { Stress/ } \\
\text { YS }\end{array}$ & $\begin{array}{l}\text { Stress } \\
(\mathrm{MPa})\end{array}$ & $\begin{array}{c}\text { Stress/ } \\
\text { NTS }\end{array}$ & $\begin{array}{c}\text { Stress/ } \\
\text { YS }\end{array}$ \\
\hline Controlled rolled & 1130 & $0 \cdot 981$ & $2 \cdot 306$ & 1010 & $0 \cdot 876$ & $2 \cdot 06$ \\
\hline Normalized & 990 & 0.957 & $3 \cdot 278$ & 885 & $0 \cdot 856$ & $2 \cdot 93$ \\
\hline $\mathrm{Q} \& \mathrm{~T}$ & 1060 & 0.977 & $2 \cdot 185$ & 910 & $0 \cdot 839$ & $1 \cdot 88$ \\
\hline
\end{tabular}

fusion of hydrogen to critical levels and initiate fracture. Thus the static fatigue limit is high.

The quenched and tempered steel showed greater susceptibility to hydrogen embrittlement than the as received steel, even though both had similar tensile properties (figure 4). The QT material had martensite inter-lath interfaces, high density of dislocations and carbide-matrix interfaces all of which act as hydrogen traps. These traps were apparently not as effective in delaying hydrogen transport as those in the as-received steel. This lead to the lowering of the incubation time and failure times in the QT steel in figure 4. Presence of more potential cracknucleating sites like the sharp inter-lath boundaries and carbide-matrix interfaces and the less-efficient trapping of hydrogen lead to the lower static-fatigue limit for this material.

In the normalized steel, coarse grain size and low dislocation density decreased the number of trap sites. Hence hydrogen present in the steel readily diffuses towards potential crack nucleation sites. This has caused the material to fail after the shortest exposure periods seen in figure 4.

The present results are in good agreement with previously reported results (Pressouyre 1982).

\section{Conclusions}

The major conclusions drawn from the present study may be following:

(I) API X-65 steel is susceptible to hydrogen embrittlement.

(II) The resistance to hydrogen embrittlement is in the order of controlled rolled $>$ quenched and tempered $>$ normalized.

(III) The mode of hydrogen-induced fracture is microvoid coalescence in all conditions.

\section{Acknowledgements}

The authors acknowledge the financial support provided by the University Grants Commission through the funded project 'Hydrogen Embrittlement' as well as the Department of Metallurgical Engineering, Banaras Hindu University, through a scholarship. Special thanks are due to Prof. D S Sarma for his help in the electron microscopic studies and Dr K Ravi, Steel Authority of India, for the supply of the experimental steel.

\section{References}

Beevers J A, Chrisman T K and Parkins R N 1988 Mater. Perf. 2722

Bernstein I M, Thompson A W, Gutierrez-Solana F and Christodoulou L 1982 Current solutions to hydrogen problems in steels (eds) C G Interrante and G M Pressouyre (Metals Park, Ohio: American Society for Metals) p. 259

Li J C M, Oriani R A and Darken L S 1966 Z. Phys. Chem. (N. F.) 49271

Lopez H F, Raghunath R, Albarran J L and Martinez L 1996 Metall. Mater. Trans. A27 3601

Moor E M and Warga J 1976 Mater. Perf. 1517

Namboodhiri T K G 1984 Trans. Indian Inst. Metals 37764

Pressouyre G M 1982 Current solutions to hydrogen problems in steels (eds) C G Interrante and G M Pressouyre (Metals Park, Ohio: American Society for Metals) p. 18

Pussegoda L N and Tyson W R 1981 Hydrogen effects in metals (eds) I M Bernstein and A W Thompson (Warrendale: TMS/AIME) p. 349

Rath B B and Bernstein I M 1971 Metall. Trans. 22845

Ravi K, Ramaswamy V and Namboodhiri T K G 1990 Mater. Sci. Engg. A129 87

Troiano A R 1960 Trans. ASM 5254

Vasudevan R, Stout R O and Pense A W 1981 Welding J. 60 155 